\title{
Probabilistic and Single-Subject Retinotopic Maps Reveal the Topographic Organization of Face Patches in the Macaque Cortex
}

\author{
Thomas Janssens, ${ }^{1}$ Qi Zhu, ${ }^{1}$ Ivo D. Popivanov, ${ }^{1}$ and Wim Vanduffel ${ }^{1,2,3}$ \\ ${ }^{1}$ Laboratory for Neurophysiology and Psychophysiology, KU Leuven, 3000 Leuven, Belgium, ${ }^{2}$ Department of Radiology, Harvard Medical School, Boston, \\ Massachusetts 02115, and ${ }^{3}$ Athinoula A. Martinos Center for Biomedical Imaging, Massachusetts General Hospital, Charlestown, Massachusetts 02129
}

Face perception is crucial to survival among social primates. It has been suggested that a group of extrastriate cortical regions responding more strongly to faces than to nonface objects is critical for face processing in primates. It is generally assumed that these regions are not retinotopically organized, as with human face-processing areas, showing foveal bias but lacking any organization with respect to polar angle. Despite many electrophysiological studies targeting monkey face patches, the retinotopic organization of these patches remains largely unclear. We have examined the relationship between cortical face patches and the topographic organization of extrastriate cortex using biologically relevant, phase-encoded retinotopic mapping stimuli in macaques. Single-subject fMRI results indicated a gradual shift from highly retinotopic to no topographic organization from posterior to anterior face patches in inferotemporal cortex. We also constructed a probabilistic retinotopic atlas of occipital and ventral extrastriate visual cortex. By comparing this probabilistic map to the locations of face patches at the group level, we showed that a previously identified posterior lateral temporal face patch (PL) is located within the posterior inferotemporal dorsal (PITd) retinotopic area. Furthermore, we identified a novel face patch posterior PL, which is located in retinotopically organized transitional area V4 (V4t). Previously published coordinates of human PITd coincide with the group-level occipital face area (OFA), according to a probabilistic map derived from a large population, implying a potential correspondence between monkey PL/PITd and human OFA/PITd. Furthermore, the monkey middle lateral temporal face patch (ML) shows consistent foveal biases but no obvious polar-angle structure. In contrast, middle fundus temporal (MF), anterior temporal and prefrontal monkey face patches lacked topographic organization.

\section{Introduction}

To process facial information, primates rely on several extrastriate cortical regions that respond more strongly to faces than to a wide variety of nonface objects (Kanwisher et al., 1997; Tsao et al., 2003; Pinsk et al., 2005; Rajimehr et al., 2009). These face patches are functionally interconnected in monkeys forming a "faceprocessing network" (Moeller et al., 2008) embedded in occipitotemporal and prefrontal cortex (Pinsk et al., 2005; Hadj-Bouziane et al., 2008; Tsao et al., 2008b; Rajimehr et al., 2009; Ku et al., 2011; Zhu et al., 2011).

Although significant progress has been made in the understanding of the neuronal response characteristics of monkey face patches (Tsao et al., 2006; Hadj-Bouziane et al., 2008; Freiwald et

\footnotetext{
Received July 9, 2013; revised Oct. 9, 2013; accepted Oct. 11, 2013.

Author contributions:W.V. designed research;T.J. and I.D.P. performed research; T.J. and Q.Z. analyzed data; T.J., Q.Z., and W.V. wrote the paper.

This work was supported by Research Foundation Flanders Grants G062208.10, G083111.10, G0A56.13, G0439.12, K7148.11, and G0719.12, and EF/05/014, GOA/10/019, and IUAP 7/11. T.J. and Q.Z. are a doctoral and a postdoctoral fellow, respectively, of the FWO-Flanders. We thank A. Coeman, C. Fransen, P. Kayenbergh, G. Meulemans, and C. Van Eupen for technical support; and S. Raiguel for his comments on the manuscript.

The authors declare no competing financial interests.

Correspondence should be addressed to Wim Vanduffel, Department of Radiology, HMS, MGH, Building 149, Room 2301 13th Street, Charlestown, MA 02129. E-mail: wim@nmr.mgh.harvard.edu.

DOI:10.1523/JNEUROSCI.2914-13.2013

Copyright $\odot 2014$ the authors $\quad 0270-6474 / 14 / 3410156-12 \$ 15.00 / 0$
}

al., 2009; Pinsk et al., 2009; Freiwald and Tsao, 2010; Issa and DiCarlo, 2012), little is known about their topographic organizations. Such information, however, would be invaluable for several reasons. First, relating the face-selective regions of monkeys and humans to their respective retinotopic maps may provide a powerful tool for establishing functional correspondences across species. Since most human face areas are located outside the region containing predominantly retinotopic areas (Halgren et al., 1999; Brewer et al., 2005; Larsson and Heeger, 2006; Arcaro et al., 2009), and display only a modest degree of eccentricity bias (Levy et al., 2001; Hasson et al., 2002), it is reasonable to assume that monkey face patches are also not retinotopically organized. However, since the $3 \mathrm{D}$ coordinates of the posterior lateral (PL) face patch may correspond to that of retinotopic temporal occipital area (TEO; Boussaoud et al., 1991; Ungerleider et al., 2008; Kolster et al., 2009), and because a recent MR-guided electrophysiological study showed an upper-field preference in PL (Issa and DiCarlo, 2012), it may nonetheless be retinotopically organized.

Second, relating face patches to retinotopic areas could have important implications for inferring the nature of their neural computations (Halgren et al., 1999; Freiwald and Tsao, 2010). A face patch within retinotopic cortex presumably processes relatively low-level information specific for the location of faces (or face components) in the visual field. On the other hand, higher- 

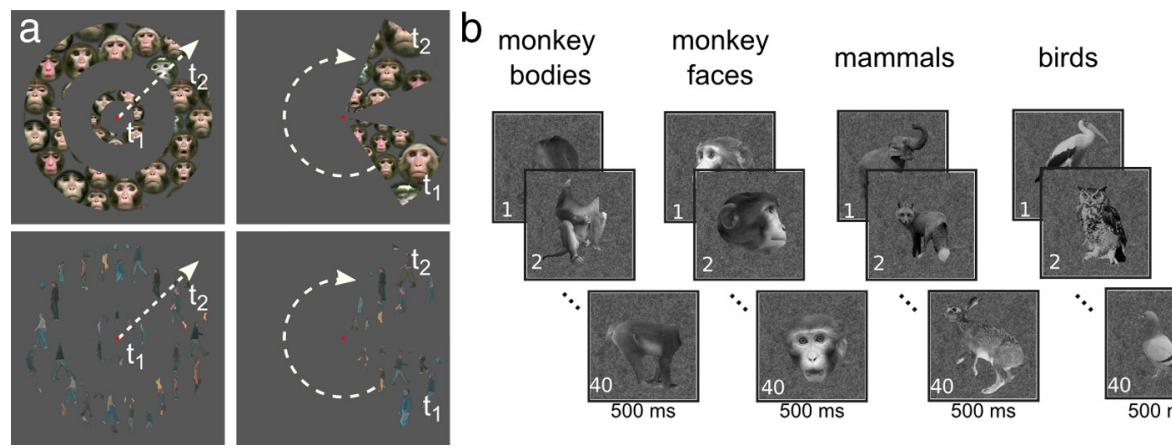

objects

fruits/ vegetables

fixation
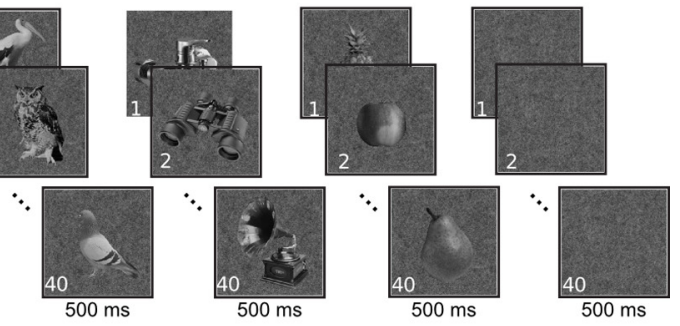

Figure 1. The experimental stimuli. $\boldsymbol{a}$, Animated movies of monkey faces (top) and walking humans (bottom) confined to eccentricity rings and polar-angle wedges. Cycle period, $64 \mathrm{~s} ; 4$ cycles/run; apertures between $0.25^{\circ}$ and $12.25^{\circ}$; wedge width, $45^{\circ}$. $\boldsymbol{b}$, Block design experiment using images from six different categories (monkey bodies, monkey faces, mammals, birds, objects, and fruits/vegetables) and one fixation-only condition. The contrast monkey faces versus objects was used to localize the face patches. Panel $\boldsymbol{b}$ is modified with permission from Popivanov et al., 2012.

level processing, requiring invariant facial representations comprising invariances for changes in size, viewpoint, or location, is more difficult to reconcile with a rigid retinotopic organization. Processes involved in face identification are thus assumed to depend on the integration of information converging at higher levels of the visual system. Obviously, the reverse does not hold true, and a lack of retinotopic organization does not necessarily imply invariant processing.

To examine the detailed retinotopic organization of face patches in monkeys, we used high-resolution fMRI and biologically relevant images superimposed onto the retinotopic stimuli. Since previous studies investigating face patches often relied on anatomically defined atlases, we have also constructed a probabilistic retinotopic atlas of monkey ventral extrastriate cortex that can be used to compare past, and to guide future, fMRI, electrophysiology (Issa and DiCarlo, 2012; Popivanov et al., 2012), and focal-perturbation experiments (Ekstrom et al., 2008; Gerits et al., 2012; Wilke et al., 2010, 2012).

\section{Materials and Methods}

Subjects and behavior

Four juvenile to young adult macaque monkeys [M1-M4, Macaca mulatta; 4-7 kg; one female (M3)] participated in this study. Animal care and experimental procedures conformed to the European and national guidelines, and were approved by the local ethical committee. The animals were prepared for awake, contrast agent-enhanced fMRI experiments, as previously described (Vanduffel et al., 2001), and were trained for a passive fixation task wherein subjects were fixed in the "sphinx" position inside a plastic box using a physical head restraint.

\section{Visual stimulus design and presentation}

Visual stimuli were rear projected using a Barco LCD projector $(1280 \times$ 1024 pixels; $60 \mathrm{~Hz}$ ) onto a translucent screen placed $56 \mathrm{~cm}$ from the monkey's eyes. During the experiment, the monkey's continuous central fixation was monitored at $120 \mathrm{~Hz}$ with an infrared-based eye-tracking system (ISCAN).

\section{Experiment 1: retinotopy}

The phase-encoded retinotopic stimuli consisted of alternating rotating wedges and expanding rings used to obtain information about both polar-angle and eccentricity organization (Engel et al., 1994; Sereno et al., 1995; Kolster et al., 2009). Each run consisted of four 64 s cycles, during which one of these two stimuli was displayed. During each scan session, $20-40$ runs were collected. Only those runs were considered for further analyses where the monkey fixated for $>95 \%$ of the time within a central virtual window, measuring $2^{\circ} \times 2^{\circ}$ visual angle around the fixation point.

To enhance neuronal responses in higher-order cortical areas, videos of either dynamic macaque faces [extracted from the movies used in Zhu et al. (2012)] or walking humans were confined to retinotopic-specific apertures. These apertures consisted of either expanding annuli or rotating wedges, traversing the area between $0.25^{\circ}$ and $12.25^{\circ}$ of visual angle (Fig. 1a). The wedges were $45^{\circ}$ wide, and the eccentricity annuli were scaled according to a $\log (\mathrm{r})$ law, to adapt the radial extent to the cortical magnification factor (Sereno et al., 1995). In addition, aspect ratios of the figures superimposed onto the wedges and annuli were also held constant over the entire range of eccentricities by adjusting the size of the displayed animated object according to the same $\log (\mathrm{r}) \operatorname{law}$. The breadths of the polar-angle wedges in the azimuthal direction and the lengths of the expanding annuli in the radial direction were specifically tailored to illuminate a given point on the screen for $8 \mathrm{~s}$, the time required for the hemodynamic response to reach its maximum (Leite and Mandeville, 2006). The initial $8 \mathrm{~s}$ of each run are used to achieve equilibrium in the hemodynamic response.

\section{Experiment 2: face localizer}

The face localizer was designed to map the locations of the face patches in the same monkeys with which the retinotopic mapping had been performed. Monkey face patch PL is located on the lateral surface of the posterior temporal gyrus, ML and MF are positioned in the lower lip and fundus of the middle superior temporal sulcus (STS), and four anterior patches [anterior fundus $(\mathrm{AF})$, anterior lateral $(\mathrm{AL})$, anterior medial $(\mathrm{AM})$, anterior dorsal $(\mathrm{AD})]$ are found in anterior inferotemporal cortex (Moeller et al., 2008; Pinsk et al., 2009). The prefrontal face patches are found in the lateral orbital sulcus $\left(\mathrm{PO}_{\mathrm{f}}\right)$, on the inferior convexity $\left(\mathrm{PL}_{\mathrm{f}}\right)$, and in the anterior bank of the lower ramus of the arcuate sulcus $\left(\mathrm{PA}_{\mathrm{f}}\right.$ Tsao et al., 2008a,b).

During the face-localizer experiment, we used a block design containing blocks (20 s each) of a fixation-only condition and six stimulus categories: monkey faces, monkey bodies, objects, mammals, birds, and fruits (Fig. 1b). This well controlled stimulus set has been described in greater detail previously (Popivanov et al., 2012). In short, low-level characteristics across the various categories were equalized insofar as possible (Popivanov et al., 2012, their Fig. 2), including corrections for mean aspect ratio and luminance. All images were embedded in pink noise with the same mean luminance and with a spatial frequency power spectrum similar to a typical natural scene. All stimuli were confined to an area averaging $5^{\circ}$ of the visual field (square root of the area). Each block contained 20 different pictures from within a single category, and each individual stimulus was presented two times per block for $500 \mathrm{~ms}$ in a pseudo-random order. Every run consisted of three cycles of $140 \mathrm{~s}$ [( six conditions + fixation block) $\times 20 \mathrm{~s}$, during which each block was shown once in pseudo-randomized order. Only runs where the monkey maintained fixation inside a $2^{\circ} \times 2^{\circ}$ virtual central window for $>90 \%$ of the time were considered for further analysis. Face-localizer data were collected in three of the four subjects (M1, M3, and M4).

\section{Data acquisition}

Anatomical scans. High resolution, T1-weighted anatomical images were collected on a whole-body Siemens TIM Trio $3 \mathrm{~T}$ scanner for use in 
conjunction with the activation overlays from the functional analyses. Under ketamine-xylazine anesthesia, an MPRAGE sequence (208 sagittal slices; $320 \times 260$ in-plane matrix; spatial resolution, $0.4 \times 0.4 \times 0.4$ $\mathrm{mm}^{3}$ ) was used to obtain $12-15$ whole-brain volumes, which were then averaged to improve signal-to-noise ratio. For subjects M1 and M4, scan parameters were set to repetition time (TR) of $2.2 \mathrm{~s}$, echo time (TE) of $2.52 \mathrm{~ms}$, inversion time (TI) of $900 \mathrm{~ms}$, and flip angle $(\alpha)$ of $9^{\circ}$. For subjects M2 and M3, the scan parameters were slightly altered to increase gray matter-white matter contrast (TR, $2.5 \mathrm{~s}$; TE, $4.35 \mathrm{~ms}$; TI, $850 \mathrm{~ms} ; \alpha$, $\left.9^{\circ}\right)$. A single-loop transmit-receive surface coil ( $12.5 \mathrm{~cm}$ diameter) constructed in-house was used for subjects M1 and M4. For subjects M2 and $\mathrm{M} 3$, data were collected with a receive-only surface coil of our own design and using the standard body transmitter.

Functional scans. All functional volumes were acquired with the same Siemens TIM Trio $3 \mathrm{~T}$ scanner. For experiment 1, a gradient-echo echoplanar imaging sequence was used (TR, $2 \mathrm{~s}$; TE, $19 \mathrm{~ms} ; \alpha, 76^{\circ}$; acceleration factor, $3 ; 1 \mathrm{~mm}^{3}$ isotropic voxels; matrix size, $84 \times 84 ; 50$ slices). For experiment 2 , data were collected with the same sequence but at $1.25 \mathrm{~mm}$ isotropic spatial resolution and with a TE of $17 \mathrm{~ms}$. Functional data were collected using an in-house-designed eight-channel, receive-only, phased-array coil and a local radial transmit coil. Immediately before each scanning session, the iron oxide contrast agent Sinerem (Guerbet) or Feraheme (AMAG Pharmaceuticals) was injected into the femoral/ saphenous vein below the knee $(8-11 \mathrm{mg} / \mathrm{kg})$. Data were acquired over multiple scanning sessions for each subject. In experiment 1 , a total of 33,000 volumes were acquired during the retinotopy experiment (M1, 7128 volumes in two sessions; M2, 11,616 volumes in three sessions; M3, 5676 volumes in two sessions; and M4, 8580 volumes in three sessions). In experiment 2, 17,220 volumes were acquired with the face-localizer stimuli (M1, 6720 volumes in one session; M3, 4620 volumes in one session; and M4, 5880 volumes in two sessions).

\section{Data analysis}

The individual anatomical images were segmented with FreeSurfer 5.0 (http://surfer.nmr.mgh.harvard.edu). The resulting white matter surfaces were inflated and flattened. All functional data from the corresponding subject were projected onto these surfaces.

Raw functional data from each scan session were reconstructed offline using an in-house developed SENSE image reconstruction algorithm and nonrigid, slice-by-slice distortion correction (Kolster et al., 2009) in MATLAB (MathWorks). The standard rigid motion correction in FreeSurfer was then applied. In experiment 1 , intersession registration was performed using $2 \mathrm{D}$ nonlinear warping in the imaging plane with JIP (www.nitrc.org/projects/jip; Mandeville et al., 2011). For each subject, one session-averaged functional image was taken as a template, and the session-averaged image from the other sessions was warped to this template. No volume smoothing was applied. After warping, the phaseencoded retinotopy data were analyzed in the native space of the template session using FS-FAST. The resulting phase information was registered with JIP (2D nonlinear registration) to match the segmented anatomical image and was projected onto the surface using FreeSurfer. To limit contributions from white matter and CSF, the average activity along the normal vector, lying between $20 \%$ and $80 \%$ of the cortical thickness, and measured at intervals of $10 \%$ of this distance, was calculated and assigned to each node on the surface. In addition, this method limits potential crossover between signals from adjacent superficial layers of gray matter in the two banks of a sulcus. The resulting eccentricity and polar-angle maps were smoothed, on the surface only, by a single smoothing step in FreeSurfer (each vertex value is averaged with its nearest neighbors), and the maps were thresholded at a significance level of $p<0.01$, uncorrected for multiple comparisons. In addition, field-sign maps (Sereno et al., 1994, 1995) were produced using the standard algorithm in FreeSurfer. In short, the angle between the polar-angle gradient and the eccentricity gradient is computed for each surface vertex. If this angle is smaller or larger than $180^{\circ}$, the vertex is classified as mirrored or nonmirrored, respectively. Unlike the eccentricity and polar-angle maps, the data for the field-sign maps were volumetrically smoothed before the general linear model (GLM) analysis to $1.25 \mathrm{~mm}$ isotropic voxels to increase the homogeneity of the maps. Regions of interest (ROIs) were assigned based on the field-sign maps for multiple visual areas for each individual subject. The borders were drawn at the transitions of the field-sign maps.

The cyclic progression of the polar angle determines the locations of the vertical and horizontal meridians separating discrete visual areas. In general, isopolar angle lines are perpendicular to isoeccentricity lines. The cyclic spatial pattern of the polar angle was quantified by sampling all polar-angle values along an isoeccentricity line $\left(\sim 3^{\circ}\right.$ of visual angle $)$ that crosses all identified visual areas. The isoeccentricity line was drawn manually on the inflated white matter surface of each hemisphere, based on the eccentricity data (i.e., independently of the polar-angle data). The precise locations of the $\sim 3^{\circ}$ values were determined by changing the color display for phase-encoded data in tksurfer (i.e., setting the number of angle cycles to 10 so that the colors cycled rapidly across different eccentricity values). The polar-angle data along the vertices on the individual paths were normalized in Matlab by interpolation so that there were exactly 50 data points between two subsequent extremal points. Finally, the polar-angle values were smoothed using a running average across the individual data points with a filter kernel of five data points.

The face-localizer data in experiment 2 were analyzed in a similar manner with a standard GLM based on SPM5 (Welcome Trust Centre). Standard motion correction was performed with SPM5, and no smoothing was applied. The contrast between faces and objects was calculated and used for identifying face patches. Contrasting faces and all other stimuli produces very similar results (Popivanov et al., 2012), hence we used only the former contrast. The resulting statistical $t$ score maps were then registered to the anatomical image and projected onto the surface using FreeSurfer, as described above.

It should be emphasized that we do not focus here on the topography of anterior dorsal visual cortex and the parietal cortex, since no face patches were found in these regions.

\section{Probabilistic retinotopy atlas}

The 12 retinotopically defined ROIs [V1, V2, V3, V4, V4A, V4 transitional area $(\mathrm{V} 4 \mathrm{t})$, dorsal occipitotemporal area $(\mathrm{OTd})$, posterior inferotemporal dorsal (PITd), posterior inferotemporal ventral (PITv), MT, ventral medial superior temporal area (MSTv), and fundus of the superior temporal area (FST)] as well as the face patches defined in the individual subjects were registered to the F99 template surface using surface-to-surface registration in FreeSurfer. The individually registered ROIs were then combined to probabilistic ROIs and imported into Caret5 (Caret, http://brainvis.wustl.edu/wiki/index.php/Caret:About) on the macaque F99 atlas (Van Essen et al., 2012). As a final step, retinotopically defined probabilistic ROIs were compared with previously published atlases that are publicly available in Caret: FV91 (Felleman and Van Essen, 1991), PHT00 (Paxinos and Franklin, 2000), and MM11 (Markov et al., 2011).

\section{Results}

Figure 2 shows the eccentricity, polar angle, and field-sign maps from the left hemisphere of subject M2 on both inflated and flattened surfaces covering the posterior and ventral portions of this hemisphere. No consistent differences were found between the maps derived from data obtained with the "face" or "walker" stimuli (data not shown); therefore, all data were pooled to increase the statistical power of our analyses. The high isotropic spatial resolution $\left(1 \mathrm{~mm}^{3}\right.$ isotropic voxels) and salient, biologically relevant, phase-encoding stimuli allowed us to define multiple retinotopically organized areas in extrastriate visual cortex beyond what has been described thus far. Previously reported topographical organization in macaque ventral cortex was confirmed in all eight hemispheres and was observed in early visual areas (V1, V2, V3, V4; Felleman and Van Essen, 1991; Brewer et al., 2002; Fize et al., 2003) and the MT cluster, which includes areas V4t, MT, MSTv, and FST (Kolster et al., 2009). Anterior to V4, we consistently identified four additional topographically organized areas having complete hemifield representations (V4A, OTd, PITd, and PITv) in all four subjects (Kolster et al., 2014). It 

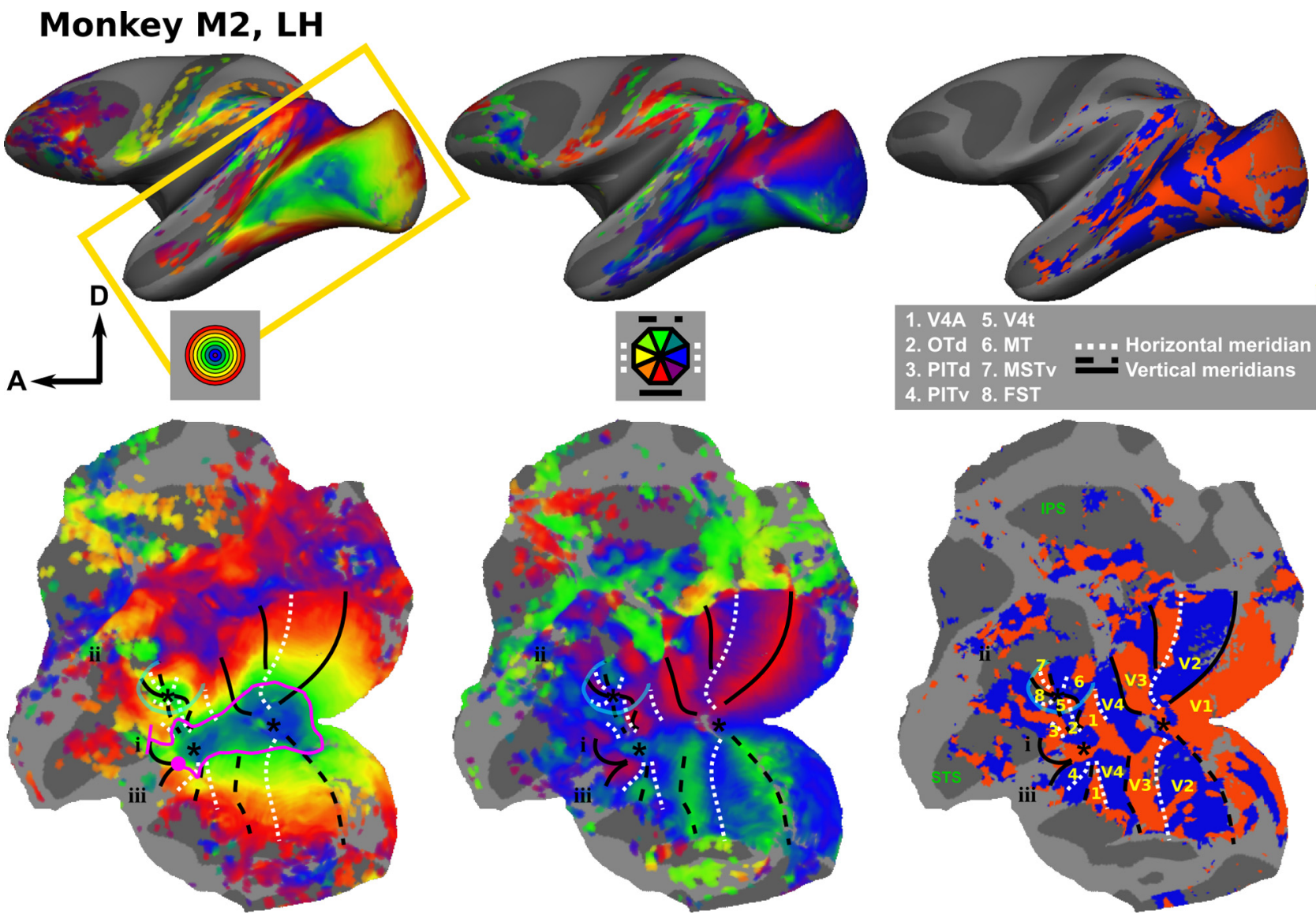

Figure 2. Retinotopic maps in the left hemisphere monkey M2. Eccentricity (left), polar-angle (middle), and field-sign (right) maps on the inflated left hemisphere (top) and on a flattened surface covering the posterior portion of the left hemisphere (bottom). The yellow rectangle on the top left figure indicates the coverage of the flattened patch. For the eccentricity (polar-angle) maps, the colors indicate the eccentricity (polar angle) to which the surface node responds best. The color code is indicated in the figure. The asterisks indicate the positions of the central visual field representations, dotted white lines indicate positions of horizontal meridians, while dashed and solid black lines delineate upper and lower vertical meridians, respectively. The field-sign maps were used to determine the positions of the meridians. The blue line indicates the eccentricity ridge around the MT cluster, and the pink line in the eccentricity map shows the isoeccentricity path used in Figure 5. i, ii, and iii indicate additional consistent eccentricity biases; see Results. All maps are thresholded at $p<0.01$.

should be noted that the areal boundaries in the present study are based entirely on objectively defined field-sign maps (Fig. 2, right panels). An identical retinotopy experiment using standard checkerboard stimuli (Kolster et al., 2014) revealed similar retinotopic organizations in all 12 reported visual areas. However, the foveal representations of the various visual field map clusters (V1-V4; V4A-OTd-PITd/v; and MT cluster) are more clearly distinguishable using the biologically relevant stimuli of the present study.

We shall first briefly summarize the properties of the visual field maps anteroventral to area V4 as obtained with the biologically relevant stimuli in the present study. A close-up of this portion of the cortex is shown in Figures 3 and 4 for the right and left hemisphere, respectively (M1, M3, and M4). The anterior border of area V4 is a representation of a horizontal meridian shared with area V4A (Dubner and Zeki, 1971; Zeki, 1971; Pigarev et al., 2002; Stepniewska et al., 2005; Roe et al., 2012). The latter area consists of two quarter-fields, one located dorsally, representing the lower contralateral quadrant [with a lower vertical meridian (VM) as anterior border], and one positioned ventrally representing the upper contralateral quadrant (with an upper VM as anterior border). V4A is located on the prelunate gyrus, consistent with previous reports (Dubner and Zeki, 1971; Zeki, 1971; Pigarev et al., 2002; Stepniewska et al., 2005; Ungerleider et al., 2008; Roe et al., 2012). The lower- field representation in dorsal V4A was consistently found to be smaller than the upper-field representation in the ventral component. Ventrally, anterior V4A borders a full hemifield that we refer to as PITv, exactly as presented in the schematic by Felleman and Van Essen (1991). Dorsally, anterior V4A borders an area that also represents a complete hemifield, but is restricted to foveal and parafoveal eccentricities. This area, referred to as OTd, is located at the intersection between the MT cluster (Kolster et al., 2009) and the field map clusters formed by the occipital (V1, V2, V3, V4), V4A, and two inferior temporal visual areas (see below). OTd is separated from neighboring area V4t within the MT cluster by an eccentricity ridge. More posteriorly, OTd borders the lower visual field representation of area V4A (with a shared lower VM), and anteriorly it shares an upper VM with another full hemifield representation, designated PITd [again, as originally described by Felleman and Van Essen (1991)]. PITd and PITV share a lower VM for the near-central representations, but one that appears to split anteriorly, for the more peripheral eccentricities.

Figures 2, 3, and 4 show that this topographic pattern remains consistent across subjects. Furthermore, the maps indicate that there are several independent visual field map clusters (Wandell et al., 2005). Each cluster contains a number of visual areas sharing a common foveal representation that is surrounded by a 
joined eccentricity map. Clearly separable foveal representations can be found in seven of eight hemispheres for the following clusters of areas: I: V1, V2, V3, and V4; II: V4A, OTd, PITd, and PITv; and III: V4t, MT, MSTv, and FST.

More anteriorly, relative to PITd and PITv, there are indications of additional consistent eccentricity biases (Figs. 2, 3, 4, i, ii, and iii). For example, anterior to the MT cluster a foveal bias can be observed that is separated by an eccentricity ridge from the more dorsally located area FST. The location of this foveal representation (Figs. 2, i, 3, i, 4, i) coincided with that of area LST as reported previously by Nelissen et al. (2006). These authors also described a foveal bias in lower superior temporal (LST) region (based on $8 \mathrm{~mm}^{3}$ voxels), which is corroborated by highresolution data ( $1 \mathrm{~mm}^{3}$ voxels) here. The polar-angle organization of this region is much less clear than its foveal bias or that of other polar-angle representations found in more posteriorly located visual areas. Furthermore, a foveal bias could be consistently identified (eight of eight hemispheres) in the superior bank of STS, anterior to the MT cluster and covered portions of area STP (Figs. 2, ii, 3, ii, 4, ii). Finally, anteriorly to PITd, PITv, and LST in the lower bank of the STS, small patches of foveal bias were found that exceeded the $p<0.01$ threshold (Figs. 2, iii, 3, iii, 4, iii).

The gray matter surface area in each of the retinotopically defined visual regions is summarized in Table 1. In general, ROIs tend to be consistent between hemispheres.

In Fig. 5, we plot the polar angle along an isoeccentricity line crossing eight areas at a fixed eccentricity of $\sim 3^{\circ}$ for all four subjects (see Materials and Methods). The isoeccentricity line is indicated on the eccentricity map for subject M2 (purple line) in Figure 2. The start and end points are indicated with a circle and vertical bar, respectively. The analysis resulted in a sinusoidal wave pattern with polar-angle values ranging from $-\pi$ to 0 for the right hemisphere (representing the left visual field), and 0 to $\pi$ for the left hemisphere (representing the right visual field). These results confirm the retinotopic organization postulated above and visualized in Figures 2, 3, and 4.

We next attempted to relate the face-localizer data (experiment 2) with the retinotopic data of the individual subjects (experiment 1). The location of the face patches (defined by the contrast monkey faces vs objects; Fig. 1b) in our dataset is largely consistent with previous studies performed in macaques (HadjBouziane et al., 2008; Tsao et al., 2008a; Pinsk et al., 2009; Rajimehr et al., 2009; Ku et al., 2011; Popivanov et al., 2012). The bottom panels of Figures 3 and 4 show the face patches on flattened representations of the STS in M1, M3, and M4. The contrast monkey faces versus all other nonface conditions revealed

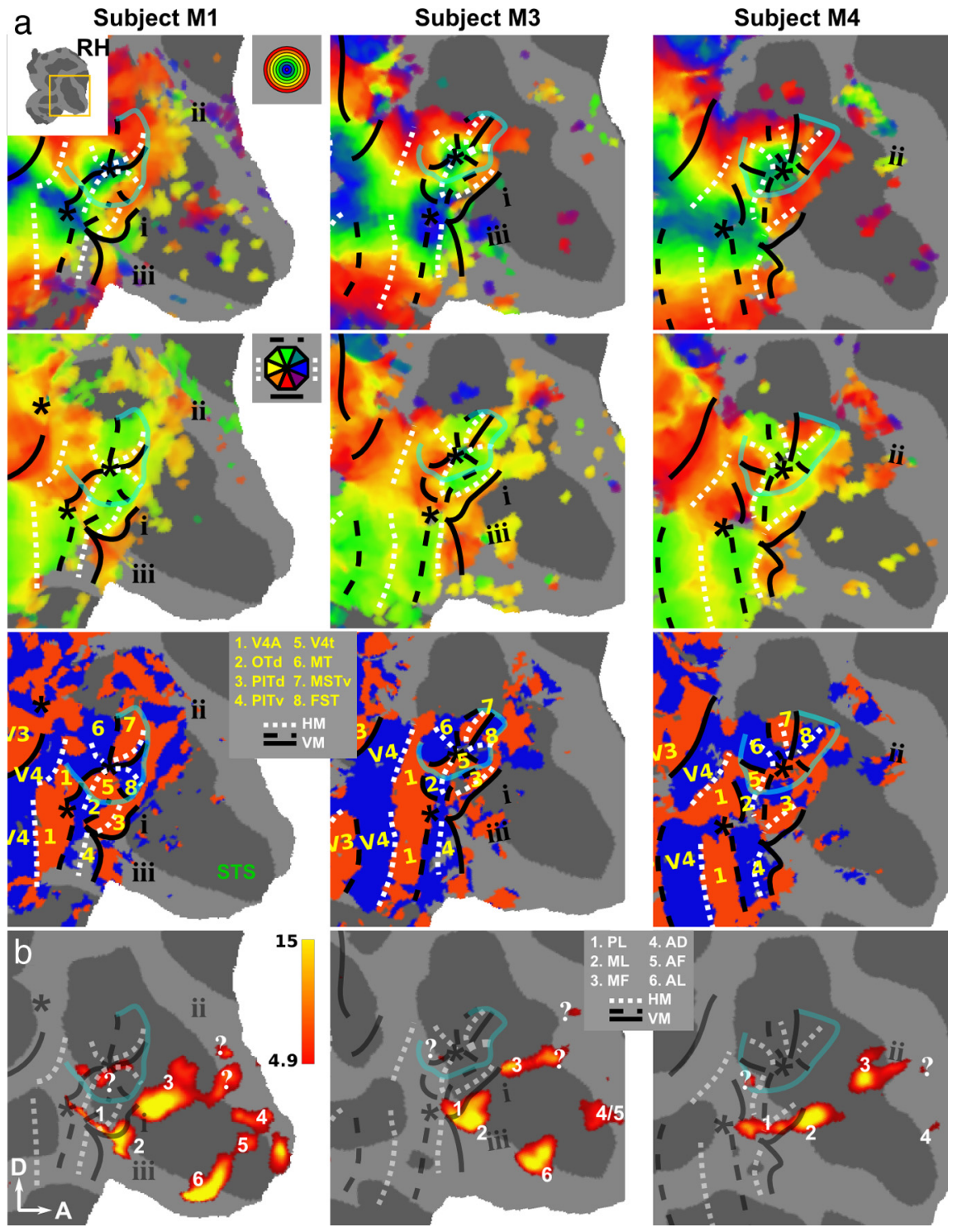

Figure 3. Retinotopic maps and face patches in occipitotemporal cortex of the right hemisphere. Results of retinotopic mapping ( olar-angle (middle), and field-sign (bottom) maps. Nomenclature is identical to Figure 2. The yellow numbers indicate the ferent areas indicated in the inset. $\boldsymbol{b}$, T-score maps for the contrast monkey face versus size-matched objects thresholded at $p<$ 0.05 , FWE corrected. The white numbers indicate the face patches according to the legend shown on the figure. "?" indicates three additional regions selectively activated by faces that have not been previously reported.

very similar results (data not shown). In six of six hemispheres, we found face patches that most likely correspond to PL, ML, and MF (Moeller et al., 2008; Tsao et al., 2008a). More anteriorly, we also found patches in the STS corresponding to AD (five of six hemispheres), $\mathrm{AF}$ (three of six hemispheres), and AL (four of six hemispheres). It needs to be noted, however, that the distinction between AD (Pinsk et al., 2009) and AF (Tsao et al., 2008a) is not always straightforward. As a result, it was not clear in either hemisphere of subject M3 whether the face patch found in the anterior superior bank corresponded to AF or AD. A similar remark can be made concerning PL and ML: In two of six hemispheres, these patches were completely separated, but were confluent in the other four of six hemispheres. Furthermore, our data revealed possible evidence of additional face patches (indicated with "?" in Figs. $3 b$ and $4 b$ ) that have not been described earlier. The most frequently observed of these was located between MF and AF/AD 

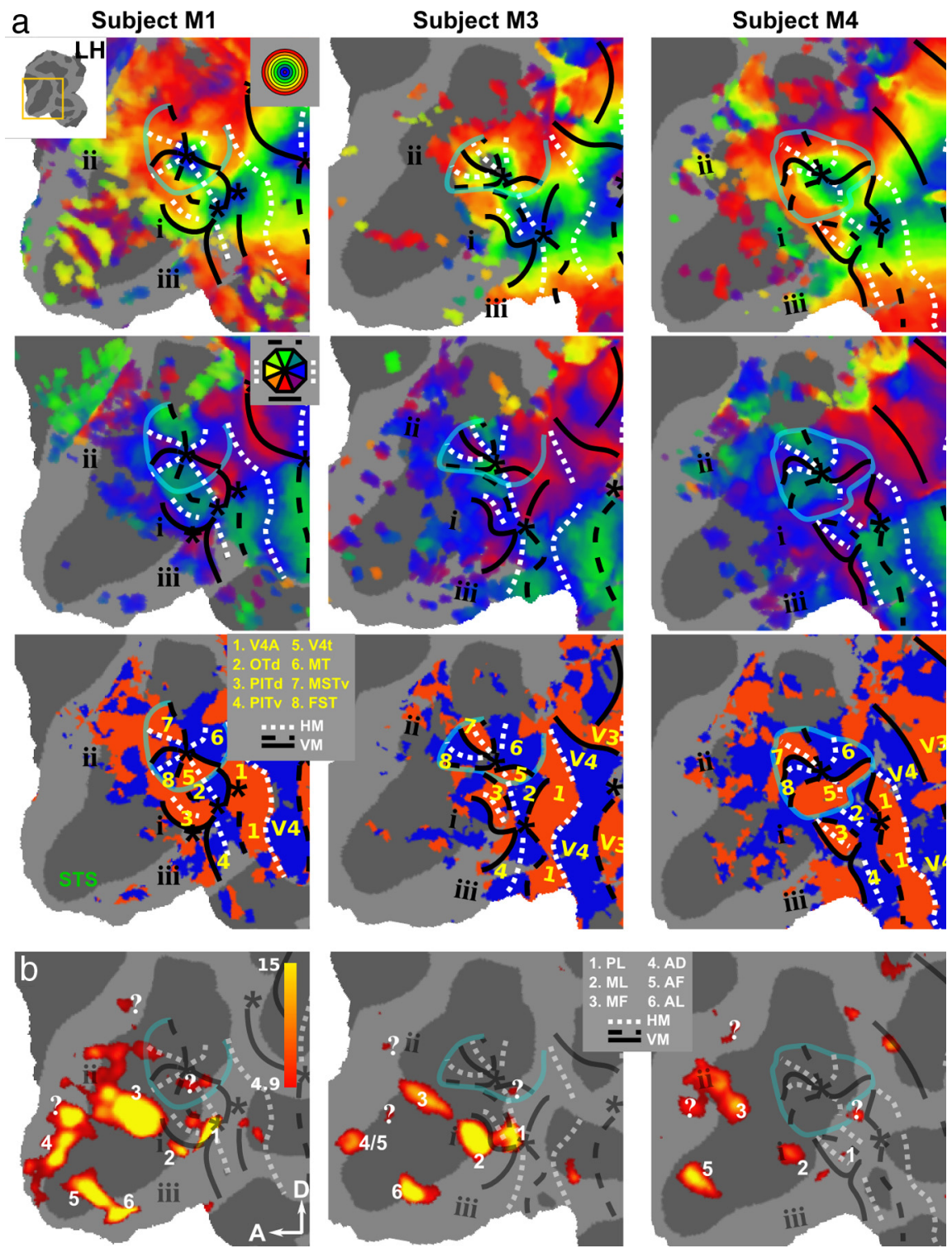

Figure 4. Retinotopic maps and face patches in occipitotemporal cortex of the left hemisphere. The results for the left hemispheres of subjects M1, M3, and M4 are shown on a flattened map zoomed in on the STS. $\boldsymbol{a}$, Eccentricity (top), polar-angle (middle), and field-sign (bottom) maps. $\boldsymbol{b}, t$ score maps for the contrast monkey face versus size-matched objects thresholded at $p<0.05$, FWE corrected. See Figures 2 and 3 for nomenclature.

Table 1. Surface areas (mean \pm SEM) of individual cortical areas averaged across the four subjects for the left and right hemispheres independently and averaged over the left and right hemisphere

\begin{tabular}{llll}
\hline ROI & Surface area LH $\left(\mathrm{mm}^{2}\right)$ & Surface area RH $\left(\mathrm{mm}^{2}\right)$ & Surface area LR average $\left(\mathrm{mm}^{2}\right)$ \\
\hline V1 & $646 \pm 36$ & $595 \pm 52$ & $620 \pm 44$ \\
V2 & $480 \pm 26$ & $470 \pm 47$ & $475 \pm 36$ \\
V3 & $295 \pm 13$ & $288 \pm 25$ & $292 \pm 18$ \\
V4 & $182 \pm 17$ & $178 \pm 14$ & $180 \pm 14$ \\
V4A & $103 \pm 12$ & $106 \pm 9$ & $104 \pm 10$ \\
OT & $29 \pm 4$ & $26 \pm 3$ & $27 \pm 3$ \\
PITd & $43 \pm 11$ & $34 \pm 3$ & $39 \pm 8$ \\
PITV & $55 \pm 8$ & $52 \pm 6$ & $53 \pm 7$ \\
MT/V5 & $37 \pm 3$ & $39 \pm 6$ & $38 \pm 5$ \\
MSTV & $25 \pm 4$ & $34 \pm 4$ & $30 \pm 4$ \\
FST & $26 \pm 5$ & $23 \pm 5$ & $24 \pm 4$ \\
V4t & $24 \pm 3$ & $15 \pm 2$ & $20 \pm 3$ \\
\hline
\end{tabular}

LH, Left hemisphere; RH, right hemisphere. (six of six hemispheres). A small patch was also present in V4t (four of six hemispheres) and in the superior temporal gyrus (five of six hemispheres). The activations in these patches exceeded the rather conservative threshold $(p<0.05$, FWE corrected level), which suggests that the face-processing network in monkeys is larger than has been previously suggested. These novel patches were not named on the individual surface maps. Only the activation patch between MF and $\mathrm{AF} / \mathrm{AD}$, and the patch in V4t were found at a consistent location in multiple subjects (Fig. 6), and were designated anterior MF (aMF) and posterior PL (pPL; to distinguish it from PL), respectively.

In the present study, no consistent face-selective activity above the threshold of $p<0.05$ (FWE corrected) was found at the locations of several ventral temporal face patches (e.g., in parahippocampal region, entorhinal cortex, hippocampus, and amygdala) reported by $\mathrm{Ku}$ et al. (2011). Lowering the threshold in the $t$ score maps to $t>3$, as in the study of Ku et al. (2011), revealed face-selective activity within the aforementioned ventral temporal areas, yet lying outside retinotopically organized cortex in all subjects (data not shown).

In Figures 3 and 4, the retinotopically defined borders of the individual monkeys (experiment 1) are superimposed onto the flat maps. Consistent face activations were found in PITd (six of six hemispheres), immediately anterior to PITd (six of six hemispheres), and anterior to the MT cluster in the fundus of STS ( six of six hemispheres). These face patches correspond to $\mathrm{PL}, \mathrm{ML}$, and $\mathrm{MF}$, respectively. The anterior temporal face patches are located in extrastriate visual cortex for which we could not find a consistent polar-angle or eccentricity organization (Figs. 3, 4, compare $b, a$ ), even below a threshold of $p<0.01$ (uncorrected for multiple comparisons).

After defining the visual field maps in the individual subjects, we created a probabilistic map of all identified occipitotemporal retinotopic areas on the F99 monkey template brain in FreeSurfer and Caret (Van Essen et al., 2001). More specifically, based on the visual field-sign maps, we created ROIs for each of these retinotopically defined areas in the individual subjects. It is noteworthy that the ROIs were based on objective criteria (i.e., reversals in the field-sign maps). These ROIs were then warped to the F99 monkey template surface to create a probabilistic map of these areas in this template space (Fig. 6a). The early visual areas show substantial overlap between the individual ROIs. While the center-ofmass positions of the individual higher-order areas correlated surprisingly well across subjects, intersubject differences in areal extents become more pronounced for the higher-order areas, 


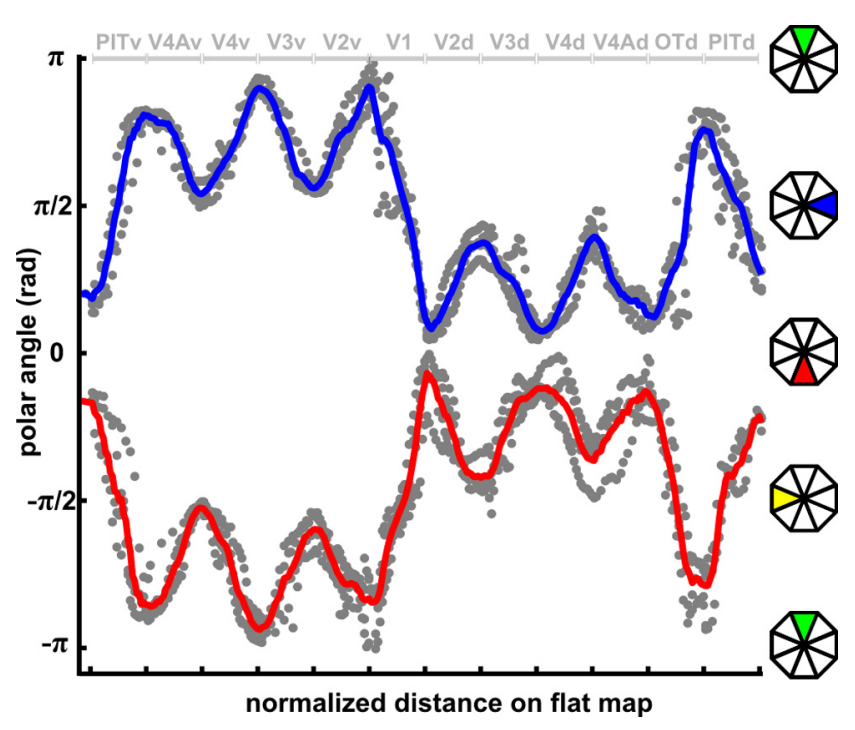

Figure 5. Group polar-angle phase plots. The polar angle was plotted along an isoeccentricity line of $\sim 3^{\circ}$ (Fig. 2, pink line) for all four subjects (gray dots). Polar-angle values (in radians) range from $-\pi$ to $\pi$. Only values above the threshold $(p<0.01)$ were plotted. The smoothed average $(n=4)$ plot of the polar-angle progression along the path in left (or right) hemisphere, corresponding to the right visual field, is shown in red (or blue).

exactly as predicted by the existing literature (Van Essen et al., 1984).

Next, we also created a probabilistic map of the face patches in inferotemporal cortex (IT) and prefrontal cortex in F99 space, based on the face-localizer data of the three monkeys that participated in experiment 2. In Figure 6b, we overlay the face patches (cyan outlines delineate regions where two of three subjects showed overlap) with the probabilistic retinotopy atlas for the right hemisphere of F99 (white outlines show retinotopic ROIs where three of four subjects showed an overlap). These group data corroborate results obtained with the individual subjects, since the posterior face activations (referred to here as PL) overlap with probabilistic PITd, while the other temporal face patches are clearly located outside retinotopically organized cortex (ML, $\mathrm{MF}, \mathrm{AL}, \mathrm{AF}$, and $\mathrm{AD})$. ML corresponds to a region immediately anterior to the MT cluster and PITd with a foveal bias that could correspond to LST as described by Nelissen et al. (2006) (see above). Note that of the three aforementioned face-selective patches not yet described in the literature, two are found at a consistent location (in two of three monkeys). The patch lying between $\mathrm{MF}$ and $\mathrm{AF} / \mathrm{AD}$ in the superior temporal gyrus is therefore referred to as aMF. The patch in retinotopic area V4t is designated the pPL face patch, in keeping with existing nomenclature. The location of face-selective activations in the upper bank of STS was not consistent across subjects. In a final group analysis, we computed the probability of cortex-outside the aforementioned 12 retinotopic areas-showing consistent but nonetheless subthreshold foveal biases $\left(0-4^{\circ}\right.$ eccentricity, below $p<0.01$, uncorrected threshold; Fig. $6 c$ ). The polar-angle values in these foveal bias zones were also below threshold, although a contralateral preference was consistently observed below threshold. This probability analysis revealed three distinct zones of subthreshold foveal biases, one elongated region immediately anterior to the MT cluster in the superior bank of the STS, covering most of area STP, and two separate zones with foveal biases located rostroventrally relative to PITd and PITv. Posterior face patch ML is clearly located within such a region showing a foveal bias immediately anterior to PITd and PITv. MF is located just next to this consistently foveal region and neighbors the foveal bias zone corresponding to STP in the superior bank of the STS. Interestingly, the anterior face patches $\mathrm{AL}, \mathrm{AF}$, and $\mathrm{AD}$ are localized immediately anterior to the anteriormost portion of IT showing a foveal bias. This latter region, which partially overlapped with anterior face patch AL, is mostly interspersed between the middle and anterior face patches.

Figures 7 and 8 show the eccentricity and polar-angle maps together with the face patches in the prefrontal cortex of the left and right hemispheres respectively (M1, M3, and M4). A reasonably consistent eccentricity map can be distinguished in the prefrontal cortex of all four subjects (only three are shown) in a location corresponding to the frontal eye fields (FEFs). The central representation lies at the genu of the arcuate sulcus. The peripheral representation extends mostly anteromedially (as predicted from previous single-unit and fMRI studies; Bruce and Goldberg, 1985; Schall, 1997; Wardak et al., 2010) and ventrally relative to the central representation. The polar-angle map indicates a large contralateral hemifield representation, but one having no clear organization. In two monkeys (M3 and M4), we also observed ipsilateral representations, mainly in ventral premotor cortex (Fig. 7). In general, however, the polar-angle maps are rather inconsistent, with only a hint of two hemifield representations near FEF (e.g., alternating red-green-red colors for the right hemisphere in all three monkeys).

Based on the face-localizer data, we can identify (at $p<0.05$, FWE corrected level) two to three frontal face patches, as previously described by Tsao et al. (2008b): $\mathrm{PO}_{\mathrm{f}}$ (three of six hemispheres), $\mathrm{PL}_{\mathrm{f}}$ (six of six hemispheres), and $\mathrm{PA}_{\mathrm{f}}$ (three of six hemispheres). All three of these prefrontal patches are also present on the probabilistic map of the right hemisphere of F99 (Fig. 6b).

We observed virtually no overlap between the locations of the prefrontal face patches (Figs. 7, 8, $a, b$, white outlines) and the regions showing some degree of eccentricity and polar-angle organization, suggesting that the prefrontal face patches have no topographic organization.

The ROIs corresponding to the aforementioned retinotopically organized areas were defined for all four subjects and registered to the F99 monkey template brain in Caret. A comparison with four commonly used atlases [FV91 (Felleman and Van Essen, 1991), LV00 (Lewis and Van Essen, 2000a, b), PHT00 (Paxinos and Franklin, 2000), MM11 (Markov et al., 2011)] is presented for the right hemisphere in Figure 9. Names, numbers, sizes, and positions of higher-order visual areas (those in the current study including V4A, OTd, PITd/v, V4t, MT, MSTv, and FST) vary from atlas to atlas, hampering direct comparison. However, there is a reasonably good correspondence between the atlases and the probabilistic maps (thresholded at three of four subjects or $75 \%$ ) for the more dorsal parts of the early visual areas (V1-V3). Dorsal V4, as defined in the FV91, LV00, and PHT00 atlases, is split into dorsal V4 and V4A in the present dataset. Our probabilistic maps deviate significantly from published atlases for most upper-field representations in the ventral parts of areas V2, V3, and also V4. For example, ventral V2 of FV91, LV00, and PHT00 correspond to a combination of ventral V2 and V3, and even to parts of ventral V4 in the probabilistic map. Ventral V4 of the FV91 and PHT00 atlases is also split into V4 and V4A in the probabilistic map. Retinotopic area MT corresponds reasonably well to its definition in FV91 and MM11. The fact that MT extends further posterior in the STS in the two published atlases may be a consequence of the restricted size of the stimuli used in the present retinotopic mapping experiment ( $12.5^{\circ}$ eccentricity). 


\section{a RH, F99 surface}
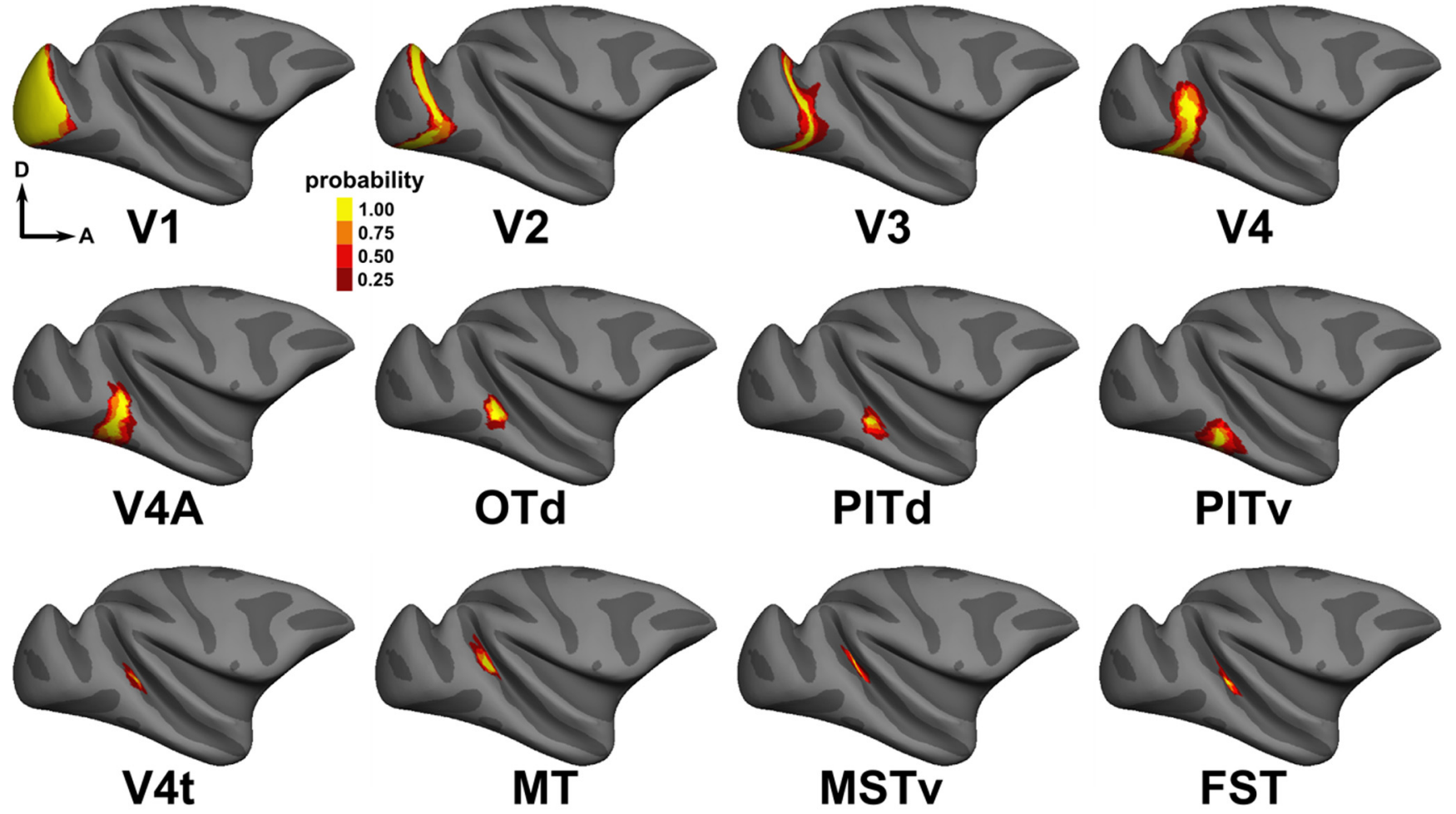

\section{b $\mathbf{R H}, \mathbf{F 9 9}$ surface}

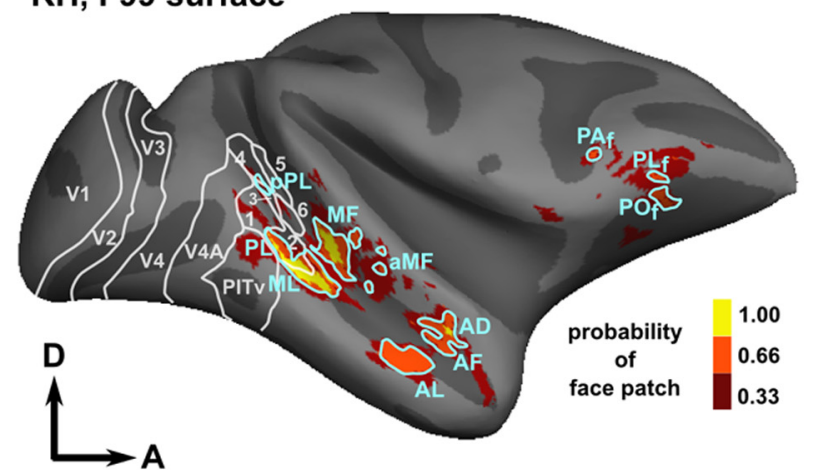

C

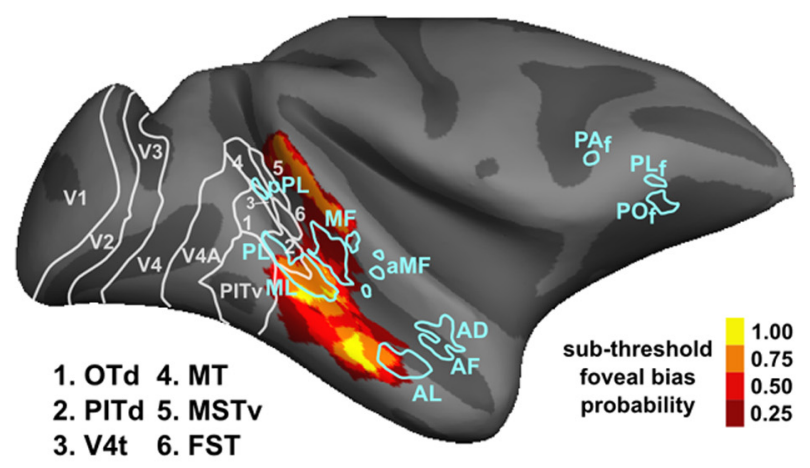

Figure 6. Probabilistic retinotopic and face patch ROIs on the F99 template in FreeSurfer. $\boldsymbol{a}$, The probabilistic ROIs of all retinotopic areas within the ventral stream that were defined above are shown on the inflated surface of the $\mathrm{F9} 9$ template brain (right hemisphere). There is a large intersubject correspondence for the definitions of the borders of early visual areas. $\boldsymbol{b}$, Location of the probabilistic group-level face patches (cyan outlines indicate a consistent face patch location in at least two of the three subjects, thresholded at $p<0.05$, FWE corrected). The $75 \%$ probability retinotopic ROIs are shown in white. All known occipitotemporal face patches that were identified in the individual subjects also survived the intersubject analysis. c, Comparison with the consistent, but below-threshold, eccentricity biases in IT cortex. Three main zones having eccentricity biases can be identified consistently as described in Results.

Also, retinotopically based definitions of PITd and PITv only partially conform with the original maps shown in FV91. For example, probabilistic OTd together with retinotopically defined PITd fit with the original definition of PITd in the FV91 atlas. PITv corresponds well to the posterior part of the PITv definition in FV91, although it also includes part of VOT in the latter atlas. Probabilistic PITv corresponds surprisingly well to TEO in the PHT00, but not in the MM11 atlas.

\section{Discussion}

We investigated the topographic organization of the face patches and surrounding cortex in macaque monkeys. The posterior face activations PPL and PL are located within retinotopically organized areas V4t and PITd, respectively. Cortex corresponding to the more anteriorly located ML showed strong foveal bias. All other face patches in monkey anterior IT and prefrontal cortex were located in regions showing no topographic organization.

Retinotopic organization of higher-order extrastriate areas Consistent retinotopic organization was revealed in multiple higher-order cortical areas using high-resolution fMRI. The topographic maps confirmed and extended previous findings (Kolster et al., 2009; Patel et al., 2010; Arcaro et al., 2011; Kolster et al., 2014). The detected retinotopic areas are grouped into the following three field map clusters sharing foveal field representations: (1) V1, V2, V3, and V4; (2) V4A, PITd, PITv, and OTd; and (3) V4t, MT, MST, and FST. Although it is tempting to speculate concerning their respective functional roles, further studies are 

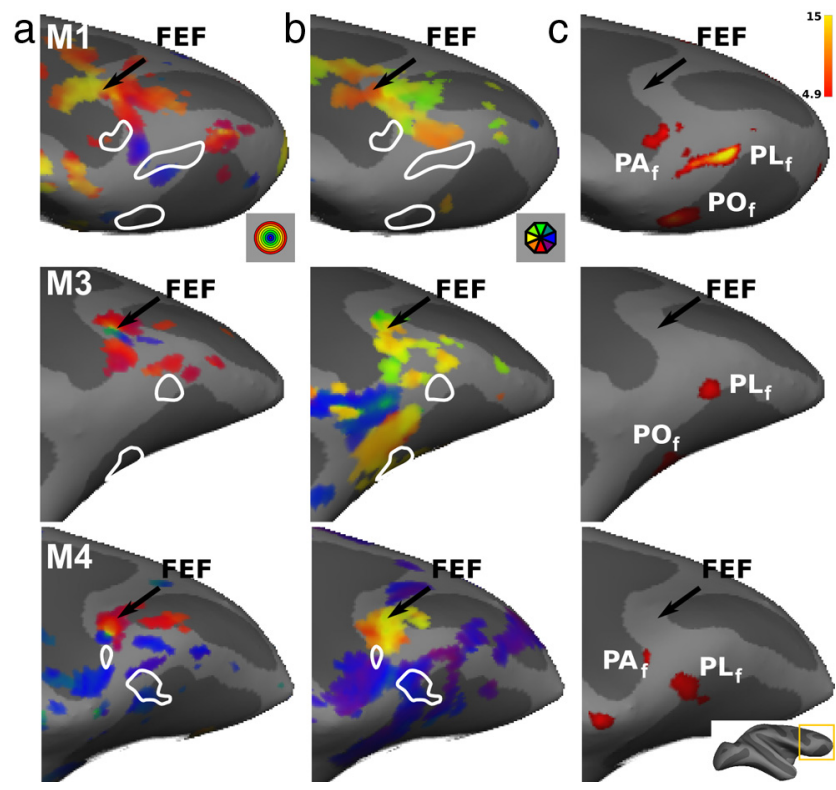

Figure 7. Retinotopy and face patches in prefrontal cortex of the right hemisphere. $\boldsymbol{a}, \mathrm{Ec}-$ centricity maps thresholded at $p<0.01$ are found in the FEF. $\boldsymbol{b}$, Polar-angle maps indicating significant polar-angle activations $(p<0.01)$ in the area around FEF but having no clear structure. $c$, $t$ score maps for the contrast monkey face versus size-matched objects thresholded at $p<0.05$, FWE corrected. The results are shown on the inflated brains of the individual subjects zoomed in on the prefrontal cortex. The white outlines shown in $\boldsymbol{a}$ and $\boldsymbol{b}$ reflect positions of the prefrontal face patches shown in $c$.
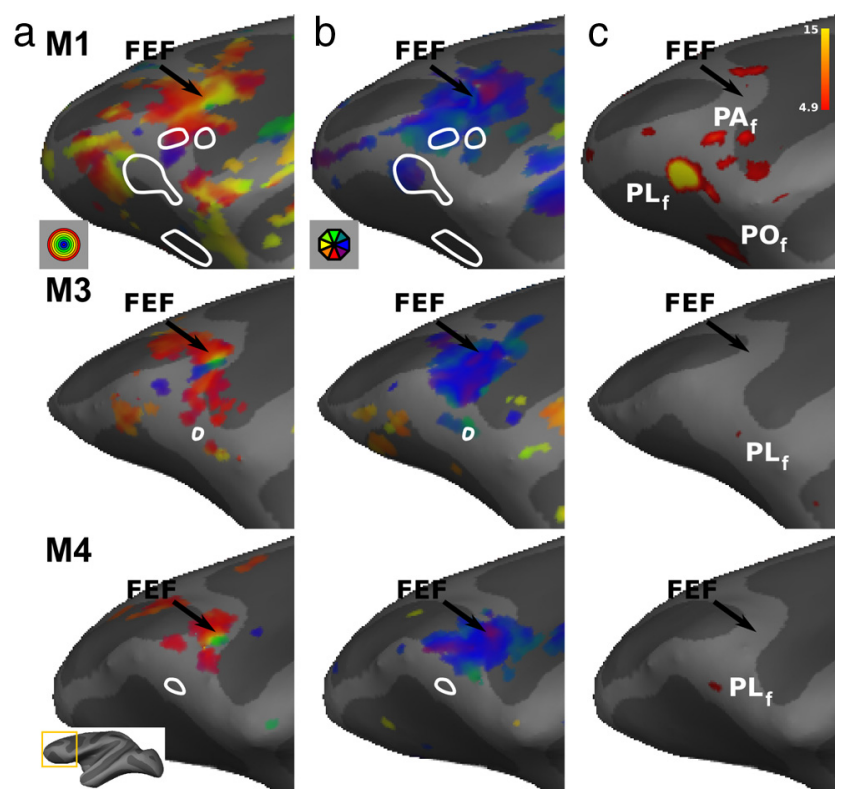

Figure 8. Retinotopy and face patches in prefrontal cortex of the left hemisphere. $\boldsymbol{a}$, Eccentricity maps. $\boldsymbol{b}$ Polar-angle maps. $\boldsymbol{c} t$ score maps for the contrast monkey face versus sizematched objects. See Figure 7 for nomenclature.

needed to ascertain whether the two far-extrastriate clusters (2 and 3) may perform distinct cluster-specific functions, as hypothesized by Wandell et al. (2005).

In addition to this highly retinotopically organized swath of extrastriate cortex, consistent eccentricity maps were identified more anteriorly in "nonretinotopic" STS, most likely corresponding to area LST (Nelissen et al., 2006), portions of STP in the upper bank of the STS, and on the middle temporal gyrus in anterior IT near the anterior middle temporal sulcus. Polar-angle organization was weak in the region encompassing ML, resulting in ambiguous polar-angle maps. It should be noted, however, that the significance values for most voxels in this latter region were clearly above threshold for the polar-angle analysis $(p<$ 0.01 ), indicating that the rather scrambled organization is probably not the result of noise. This was not the case for the anterior face patches, where no voxels reached statistically significant levels in the polar-angle or eccentricity analysis. Further anterior in IT cortex, along the lip of the posterior bank of STS, we also observed a consistent foveal bias across the three monkeys, although it did not reach significance in any individual subject. It is unlikely that this recurrent eccentricity pattern reflects mere noise. Further experiments with greater sensitivity and/or resolution are required to ascertain the relevance of this organization in middle and anterior IT cortex.

Finally, a consistent eccentricity map was identified in area FEF of prefrontal cortex, an area that was again associated with noisy polar-angle maps. These findings corroborate previously reported electrophysiological (Bruce and Goldberg, 1985; Dias and Segraves, 1999; Schall, 2002) and fMRI results (Wardak et al., 2010). Interestingly, we observed peripheral visual field representations ventrolaterally to the ramus of the arcuate, where nearfoveal receptive fields and saccade movement fields are found. In previous electrophysiological and microstimulation studies (Schall, 1997; Moore and Armstrong, 2003; Ekstrom et al., 2008), peripheral field representations or high-amplitude saccade vectors are typically found only anteriorly in the lateral bank of the upper branch of the arcuate sulcus.

\section{Probabilistic retinotopically defined ROIs}

The fMRI-based probabilistic maps on the F99 surface in both FreeSurfer and Caret provide valuable additional information about the organization of the macaque visual cortex. The resulting probabilistic ROIs are available on-line (ftp://neuroserv.med.kuleuven.be/ outgoing/JNEUROSCI/Atlases.zip). In these probabilistic ROIs, we also include retinotopic data from two additional monkeys with which phase-encoded retinotopic mapping ( $0.6 \mathrm{~mm}$ isotropic voxels) was performed using implanted phased-array coils (Janssens et al., 2012) that increase cortical signal-to-noise ratio by a factor of 3 relative to the external phased-array coils of the present study. The corresponding probabilistic maps (with $n=6$ ) are largely indistinguishable from those presented in Figures 6 and 9. The probabilistic maps will facilitate any future targeting of relevant monkey ventral stream structures using electrophysiological, fMRI, or perturbation methods.

\section{Topographic organization of the temporal face patches in} the STS

When comparing retinotopic maps of monkey ventral extrastriate cortex to the locations of the face patches, we found consistent overlap between area V4t and face patch pPL, and between area PITd and a posterior face patch, corresponding to previously reported area PL (Tsao et al., 2008a). These observations are corroborated by the findings of Issa and DiCarlo (2012), showing that PL neurons have a preference for the upper visual field. Our results using fMRI suggest that the face selectivity in PL is not limited to the upper visual field but might extend to the lower visual field (anterior portion of PITd; Figs. 2, 3). A possible explanation for this apparent discrepancy with the results from Issa and DiCarlo (2012) could be that the lower visual field representations, located more anteroventral, were not sampled in the 

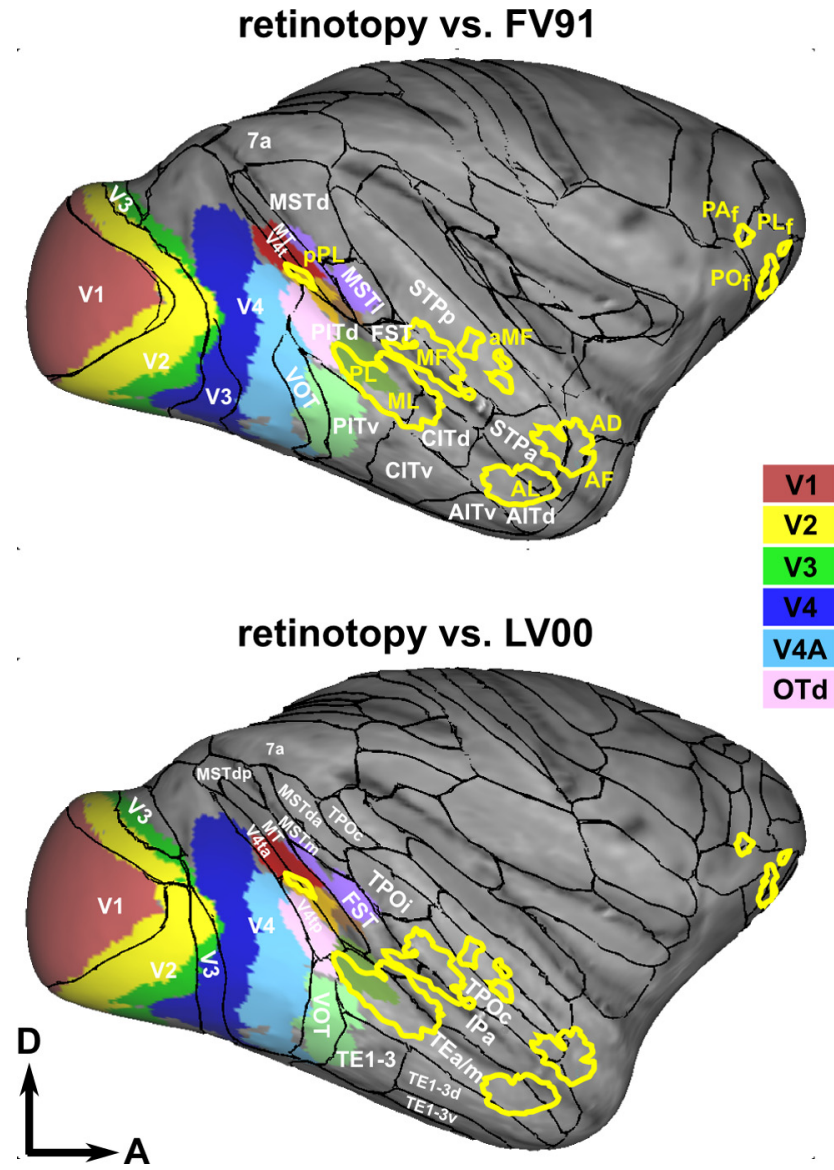

retinotopy vs. PHT00

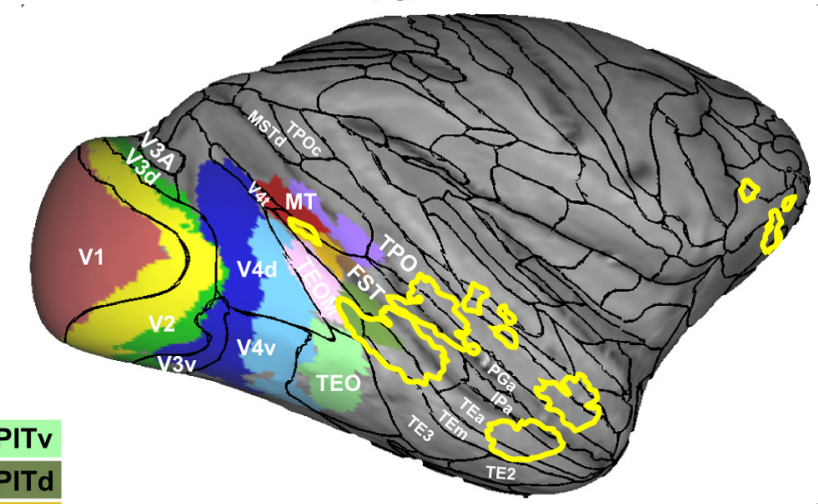

retinotopy vs. MM11

MSTV

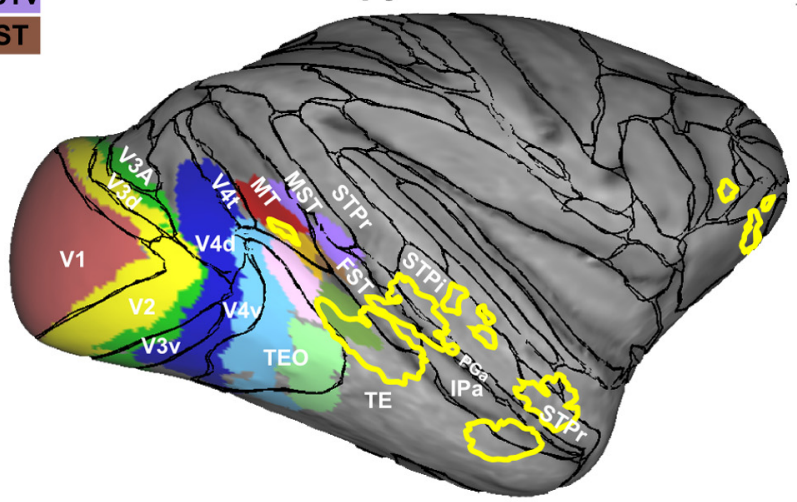

Figure 9. Comparison of probabilistic face patch and retinotopy ROIs with published atlases. Previously defined ROIs according to the atlases of FV91 (Felleman and Van Essen, 1991), LV00 (Lewis and Van Essen, 2000a,b), PHTO0 (Paxinos and Franklin, 2000), and MM11 (Markov et al., 2011) are indicated as black outlines on the inflated brain of the template subject F99 in Caret. The relevant areas of the current study are identified by name in the figure. The colored regions correspond to the $75 \%$ probability ROIs defined on the basis of retinotopy present in the current study. The yellow outlines show face-selective patches present in at least two of the three subjects, corresponding to those shown in Figure 6.

study of Issa and DiCarlo (2012). In their study, the patches ML and PL are also clearly separated.

The middle face patch ML, on the other hand, is situated within cortex showing an eccentricity bias but no clear polarangle organization. In general, these data indicate that face patches PPL, PL, and, to some extent, ML, are performing rather low-level operations on facial information. Note that in multiple individual hemispheres, face activations extended more posteriorly, to include area OTd/V4A. A direct comparison of the latter activations with respect to the posterior patches reported by Tsao et al. (2008a) is difficult since PL and ML were found to be confluent in some hemispheres in both the study by Tsao et al. (2008a) and the present study. Future experiments with higherresolution fMRI and retinotopic mapping techniques will presumably reveal more topographic detail in these posterior face patches. We also found that MF is positioned between two regions showing foveal bias, suggesting that it performs functions considerably different from those of neighboring ML. The anterior face patches $(\mathrm{AD}, \mathrm{AF}$, and $\mathrm{AL})$ show no retinotopic organization whatsoever. It is unlikely that reduced contrast-to-noise ratio could explain the lack of retinotopic signals in anterior IT, since we were consistently able to identify the face patches in this region. Hence, receptive field size and/or scatter in the neurons found in these patches are probably too large to detect topography with the used methods. In prefrontal cortex, we observed a rather consistent eccentricity map in FEF, but the frontal face patches lacked any eccentricity or polar-angle organization, sug-

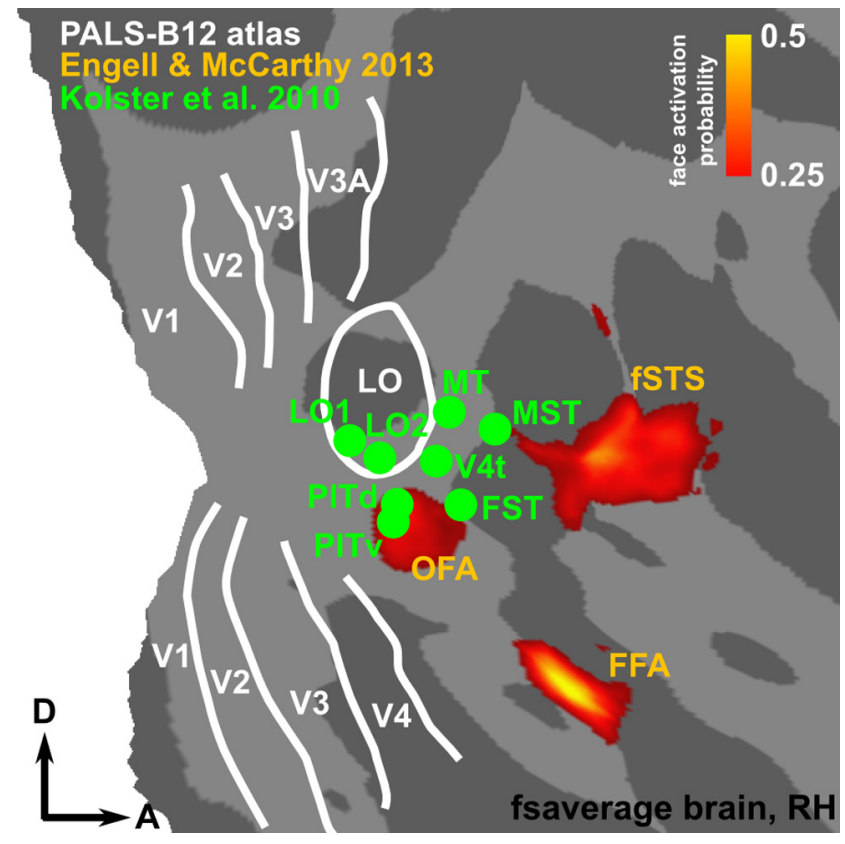

Figure 10. Human retinotopic areas and face patches. Comparison of human face patches and retinotopy obtained from the literature. The retinotopically defined areas PITd and PITv by Kolster et al. (2010) fall within the probabilistic face patch OFA (faces vs scenes, 124 subjects) of Engell and McCarthy (2013). 
gesting also that the prefrontal face patches have no underlying topographic organization. It is worth noting, however, that a negative fMRI result should be interpreted with care. Also, the size of fMRI face patches depends on signal strength and the tuning characteristics, distribution, and proportion of the faceselective cells it contains.

The various face patches within monkey visual and prefrontal cortex clearly showed differing levels of topographic organization. This supports a multiscale organization wherein some processes require fine-grained topographical organization while other processes are less dependent upon such functional organization. Furthermore, this view supports the hypothesis that a certain hierarchical organization exists among the various patches carrying out their distinct functions (Tsao et al., 2008b; Freiwald and Tsao, 2010; Issa and DiCarlo, 2012). The gradual transition from patches located in retinotopic extrastriate visual cortex, through regions showing eccentricity bias, to completely nonretinotopic cortex in anterior IT and prefrontal cortex, is consistent with a gradual shift of their functional roles from lowlevel to increasingly higher-level processing. The face patches in anterior IT and prefrontal cortex show no topographic organization, which renders them more suitable for higher-level processing requiring neuronal invariance of facial representations. This corresponds to existing literature asserting that higher-order processing, such as identity encoding, is a feature of the anterior and ventral temporal patches (Hasselmo et al., 1989; De Souza et al., 2005; Leopold et al., 2006). In addition, the face patches found in the frontal cortex are sensitive to the emotional context of faces (Tsao et al., 2008b). Both identity encoding and sensitivity to emotional context require a more global interpretation of facial information, probably relying on convergent input from lowerlevel face patches in retinotopic cortex. The more global interpretation would be less dependent on individual, topographically defined features within faces (e.g., position and features of eyes and nose), explaining the absence of any retinotopic organization in such modules.

\section{Analogy to human retinotopic areas and face patches}

Finally, these results provide information that should prove invaluable to future studies focusing on functional homologies between human and monkey retinotopic areas or face-processing modules. The face-selective response found in the monkey PITd suggests that the homologous retinotopic region in human should, in principle, also exhibit selectivity for faces. Therefore, we compared the location of the human putative homolog of PITd and PITv, as recently described (Kolster et al., 2010), with a probabilistic atlas of face activations derived from a large population (Engell and McCarthy, 2013). We found that the putative human PIT cluster largely overlaps with the probabilistic face area OFA (Fig. 10). This finding strengthens the claim of functional homology between area PITd/v in humans and monkeys and also suggests that the posterior face activation in monkey PITd, here designated PL, may be the functional homolog of OFA. Although the current study was limited to a single species, it can serve as a starting point for a more detailed and direct comparison of the topographic organization and the face-processing networks of humans and monkeys.

\section{Notes}

Supplemental material for this article is available at $\mathrm{ftp}: / /$ neuroserv.med. kuleuven.be/outgoing/JNEUROSCI/Atlases.zip. Probabilistic retinotopic atlases in F99 space. This material has not been peer reviewed.

\section{References}

Arcaro MJ, McMains SA, Singer BD, Kastner S (2009) Retinotopic organization of human ventral visual cortex. J Neurosci 29:10638-10652. CrossRef Medline

Arcaro MJ, Pinsk MA, Li X, Kastner S (2011) Visuotopic organization of macaque posterior parietal cortex: a functional magnetic resonance imaging study. J Neurosci 31:2064-2078. CrossRef Medline

Boussaoud D, Desimone R, Ungerleider LG (1991) Visual topography of area Teo in the macaque. J Comp Neurol 306:554-575. CrossRef Medline

Brewer AA, Press WA, Logothetis NK, Wandell BA (2002) Visual areas in macaque cortex measured using functional magnetic resonance imaging. J Neurosci 22:10416-10426. Medline

Brewer AA, Liu J, Wade AR, Wandell BA (2005) Visual field maps and stimulus selectivity in human ventral occipital cortex. Nat Neurosci 8:11021109. CrossRef Medline

Bruce CJ, Goldberg ME (1985) Primate frontal eye fields. I. Single neurons discharging before saccades. J Neurophysiol 53:603-635. Medline

De Souza WC, Eifuku S, Tamura R, Nishijo H, Ono T (2005) Differential characteristics of face neuron responses within the anterior superior temporal sulcus of macaques. J Neurophysiol 94:1252-1266. CrossRef Medline

Dias EC, Segraves MA (1999) Muscimol-induced inactivation of monkey frontal eye field: effects on visually and memory-guided saccades. J Neurophysiol 81:2191-2214. Medline

Dubner R, Zeki SM (1971) Response properties and receptive fields of cells in an anatomically defined region of superior temporal sulcus in monkey. Brain Res 35:528-532. CrossRef Medline

Ekstrom LB, Roelfsema PR, Arsenault JT, Bonmassar G, Vanduffel W (2008) Bottom-up dependent gating of frontal signals in early visual cortex. Science 321:414-417. CrossRef Medline

Engel SA, Rumelhart DE, Wandell BA, Lee AT, Glover GH, Chichilnisky EJ, Shadlen MN (1994) fMRI of human visual cortex. Nature 369:525. CrossRef Medline

Engell AD, McCarthy G (2013) Probabilistic atlases for face and biological motion perception: an analysis of their reliability and overlap. Neuroimage 74:140-151. CrossRef Medline

Felleman DJ, Van Essen DC (1991) Distributed hierarchical processing in the primate cerebral cortex. Cereb Cortex 1:1-47. CrossRef Medline

Fize D, Vanduffel W, Nelissen K, Denys K, Chef d'Hotel C, Faugeras O, Orban GA (2003) The retinotopic organization of primate dorsal V4 and surrounding areas: a functional magnetic resonance imaging study in awake monkeys. J Neurosci 23:7395-7406. Medline

Freiwald WA, Tsao DY (2010) Functional compartmentalization and viewpoint generalization within the macaque face-processing system. Science 330:845-851. CrossRef Medline

Freiwald WA, Tsao DY, Livingstone MS (2009) A face feature space in the macaque temporal lobe. Nat Neurosci 12:1187-1196. CrossRef Medline

Gerits A, Farivar R, Rosen BR, Wald LL, Boyden ES, Vanduffel W (2012) Optogenetically induced behavioral and functional network changes in primates. Curr Biol 22:1722-1726. CrossRef Medline

Hadj-Bouziane F, Bell AH, Knusten TA, Ungerleider LG, Tootell RB (2008) Perception of emotional expressions is independent of face selectivity in monkey inferior temporal cortex. Proc Natl Acad Sci U S A 105:55915596. CrossRef Medline

Halgren E, Dale AM, Sereno MI, Tootell RB, Marinkovic K, Rosen BR (1999) Location of human face-selective cortex with respect to retinotopic areas. Hum Brain Mapp 7:29-37. CrossRef Medline

Hasselmo ME, Rolls ET, Baylis GC (1989) The role of expression and identity in the face-selective responses of neurons in the temporal visual cortex of the monkey. Behav Brain Res 32:203-218. CrossRef Medline

Hasson U, Levy I, Behrmann M, Hendler T, Malach R (2002) Eccentricity bias as an organizing principle for human high-order object areas. Neuron 34:479-490. CrossRef Medline

Issa EB, DiCarlo JJ (2012) Precedence of the eye region in neural processing of faces. J Neurosci 32:16666-16682. CrossRef Medline

Janssens T, Keil B, Farivar R, McNab JA, Polimeni JR, Gerits A, Arsenault JT, Wald LL, Vanduffel W (2012) An implanted 8-channel array coil for high-resolution macaque MRI at 3T. Neuroimage 62:1529-1536. CrossRef Medline

Kanwisher N, McDermott J, Chun MM (1997) The fusiform face area: a module in human extrastriate cortex specialized for face perception. J Neurosci 17:4302-4311. Medline 
Kolster H, Mandeville JB, Arsenault JT, Ekstrom LB, Wald LL, Vanduffel W (2009) Visual field map clusters in macaque extrastriate visual cortex. J Neurosci 29:7031-7039. CrossRef Medline

Kolster H, Peeters R, Orban GA (2010) The retinotopic organization of the human middle temporal area MT/V5 and its cortical neighbors. J Neurosci 30:9801-9820. CrossRef Medline

Kolster H, Janssens T, Orban GA, Vanduffel W (2014) The retinotopic organization of macaque occipitotemporal cortex anterior to V4 and caudoventral to the middle temporal (MT) cluster. J Neurosci 34:10168-10191.

Ku SP, Tolias AS, Logothetis NK, Goense J (2011) fMRI of the faceprocessing network in the ventral temporal lobe of awake and anesthetized macaques. Neuron 70:352-362. CrossRef Medline

Larsson J, Heeger DJ (2006) Two retinotopic visual areas in human lateral occipital cortex. J Neurosci 26:13128-13142. CrossRef Medline

Leite FP, Mandeville JB (2006) Characterization of event-related designs using BOLD and IRON fMRI. Neuroimage 29:901-909. CrossRef Medline

Leopold DA, Bondar IV, Giese MA (2006) Norm-based face encoding by single neurons in the monkey inferotemporal cortex. Nature 442:572575. CrossRef Medline

Levy I, Hasson U, Avidan G, Hendler T, Malach R (2001) Center-periphery organization of human object areas. Nat Neurosci 4:533-539. CrossRef Medline

Lewis JW, Van Essen DC (2000a) Mapping of architectonic subdivisions in the macaque monkey, with emphasis on parieto-occipital cortex. J Comp Neurol 428:79-111. CrossRef Medline

Lewis JW, Van Essen DC (2000b) Corticocortical connections of visual, sensorimotor, and multimodal processing areas in the parietal lobe of the macaque monkey. J Comp Neurol 428:112-137. CrossRef Medline

Mandeville JB, Choi JK, Jarraya B, Rosen BR, Jenkins BG, Vanduffel W (2011) fMRI of cocaine self-administration in macaques reveals functional inhibition of basal ganglia. Neuropsychopharmacology 36:11871198. CrossRef Medline

Markov NT, Misery P, Falchier A, Lamy C, Vezoli J, Quilodran R, Gariel MA, Giroud P, Ercsey-Ravasz M, Pilaz LJ, Huissoud C, Barone P, Dehay C, Toroczkai Z, Van Essen DC, Kennedy H, Knoblauch K (2011) Weight consistency specifies regularities of macaque cortical networks. Cereb Cortex 21:1254-1272. CrossRef Medline

Moeller S, Freiwald WA, Tsao DY (2008) Patches with links: a unified system for processing faces in the macaque temporal lobe. Science 320:13551359. CrossRef Medline

Moore T, Armstrong KM (2003) Selective gating of visual signals by microstimulation of frontal cortex. Nature 421:370-373. CrossRef Medline

Nelissen K, Vanduffel W, Orban GA (2006) Charting the lower superior temporal region, a new motion-sensitive region in monkey superior temporal sulcus. J Neurosci 26:5929-5947. CrossRef Medline

Patel GH, Shulman GL, Baker JT, Akbudak E, Snyder AZ, Snyder LH, Corbetta M (2010) Topographic organization of macaque area LIP. Proc Natl Acad Sci U S A 107:4728-4733. CrossRef Medline

Paxinos G, Franklin KBJ (2000) The mouse brain in stereotaxic coordinates. San Diego, CA: Academic.

Pigarev IN, Nothdurft HC, Kastner S (2002) Neurons with radial receptive fields in monkey area V4A: evidence of a subdivision of prelunate gyrus based on neuronal response properties. Exp Brain Res 145:199-206. CrossRef Medline

Pinsk MA, DeSimone K, Moore T, Gross CG, Kastner S (2005) Representations of faces and body parts in macaque temporal cortex: a functional MRI study. Proc Natl Acad Sci U S A 102:6996-7001. CrossRef Medline

Pinsk MA, Arcaro M, Weiner KS, Kalkus JF, Inati SJ, Gross CG, Kastner S (2009) Neural representations of faces and body parts in macaque and human cortex: a comparative FMRI study. J Neurophysiol 101:25812600. CrossRef Medline

Popivanov ID, Jastorff J, Vanduffel W, Vogels R (2012) Stimulus representations in body-selective regions of the macaque cortex assessed with event-related fMRI. Neuroimage 63:723-741. CrossRef Medline

Rajimehr R, Young JC, Tootell RB (2009) An anterior temporal face patch in human cortex, predicted by macaque maps. Proc Natl Acad Sci U S A 106:1995-2000. CrossRef Medline

Roe AW, Chelazzi L, Connor CE, Conway BR, Fujita I, Gallant JL, Lu H, Vanduffel W (2012) Toward a unified theory of visual area V4. Neuron 74:12-29. CrossRef Medline

Schall JD (1997) Visuomotor areas of the frontal lobe. In: Cerebral cortex: extrastriate cortex of primates (Rockland KS, Kaas JH, Peters A, eds.), pp 527-638. New York: Plenum.

Schall JD (2002) The neural selection and control of saccades by the frontal eye field. Philos Trans R Soc Lond B Biol Sci 357:1073-1082. CrossRef Medline

Sereno MI, McDonald CT, Allman JM (1994) Analysis of retinotopic maps in extrastriate cortex. Cereb Cortex 4:601-620. CrossRef Medline

Sereno MI, Dale AM, Reppas JB, Kwong KK, Belliveau JW, Brady TJ, Rosen BR, Tootell RB (1995) Borders of multiple visual areas in humans revealed by functional magnetic resonance imaging. Science 268:889-893. CrossRef Medline

Stepniewska I, Collins CE, Kaas JH (2005) Reappraisal of DL/V4 boundaries based on connectivity patterns of dorsolateral visual cortex in macaques. Cereb Cortex 15:809-822. CrossRef Medline

Tsao DY, Freiwald WA, Knutsen TA, Mandeville JB, Tootell RB (2003) Faces and objects in macaque cerebral cortex. Nat Neurosci 6:989-995. CrossRef Medline

Tsao DY, Freiwald WA, Tootell RB, Livingstone MS (2006) A cortical region consisting entirely of face-selective cells. Science 311:670-674. CrossRef Medline

Tsao DY, Moeller S, Freiwald WA (2008a) Comparing face patch systems in macaques and humans. Proc Natl Acad Sci U S A 105:19514-19519. CrossRef Medline

Tsao DY, Schweers N, Moeller S, Freiwald WA (2008b) Patches of faceselective cortex in the macaque frontal lobe. Nat Neurosci 11:877-879. CrossRef Medline

Ungerleider LG, Galkin TW, Desimone R, Gattass R (2008) Cortical connections of area V4 in the macaque. Cereb Cortex 18:477-499. CrossRef Medline

Van Essen DC, Lewis JW, Drury HA, Hadjikhani N, Tootell RB, Bakircioglu M, Miller MI (2001) Mapping visual cortex in monkeys and humans using surface-based atlases. Vision Res 41:1359-1378. CrossRef Medline

Van Essen DC, Glasser MF, Dierker DL, Harwell J (2012) Cortical parcellations of the macaque monkey analyzed on surface-based atlases. Cereb Cortex 22:2227-2240. CrossRef Medline

Van Essen D, Newsome WT, Maunsell JH (1984) The visual field representation in striate cortex of the macaque monkey: asymmetries, anisotropies and individual variability. Vision Res 24:429-448. Medline

Vanduffel W, Fize D, Mandeville JB, Nelissen K, Van Hecke P, Rosen BR, Tootell RB, Orban GA (2001) Visual motion processing investigated using contrast agent-enhanced fMRI in awake behaving monkeys. Neuron 32:565-577. CrossRef Medline

Wandell BA, Brewer AA, Dougherty RF (2005) Visual field map clusters in human cortex. Philos Trans R Soc Lond B Biol Sci 360:693-707. CrossRef Medline

Wardak C, Vanduffel W, Orban GA (2010) Searching for a salient target involves frontal regions. Cereb Cortex 20:2464-2477. CrossRef Medline

Wilke M, Turchi J, Smith K, Mishkin M, Leopold DA (2010) Pulvinar inactivation disrupts selection of movement plans. J Neurosci 30:8650 -8659. CrossRef Medline

Wilke M, Kagan I, Andersen RA (2012) Functional imaging reveals rapid reorganization of cortical activity after parietal inactivation in monkeys. Proc Natl Acad Sci U S A 109:8274-8279. CrossRef Medline

Zeki SM (1971) Cortical projections from 2 prestriate areas in monkey. Brain Res 34:19-35. Medline

Zhu Q, Nelissen K, Orban GA, Vanduffel W (2011) The representation of dynamic facial expressions in the monkey frontal lobe. Soc Neurosci Abstr 37:487.20.

Zhu Q, Nelissen K, den Stock JV, De Winter FL, Pauwels K, de Gelder B, Vanduffel W, Vandenbulcke M (2012) Dissimilar processing of emotional facial expressions in human and monkey temporal cortex. Neuroimage 66C:402-411. CrossRef Medline 